\title{
Macrolide and fluoroquinolone associated mutations in Mycoplasma genitalium in a retrospective study of male and female patients seeking care at a STI Clinic in Guangzhou, China, 2016-2018
}

Wujian Ke ${ }^{1,2+}$, Dongling $\mathrm{Li}^{1,2+}$, Lai Sze Tso ${ }^{3,4,5+}$, Ran Wei ${ }^{6+}$, Yinyuan Lan ${ }^{7}$, Zhengyu Chen ${ }^{1,2}$, Xiaohui Zhang ${ }^{1,2}$, Liuyuan Wang ${ }^{1,2}$, Chunmei Liang ${ }^{1,2}$, Yuying Liao ${ }^{1,2}$, Huiru Chen ${ }^{1,2}$, Yahui Liü ${ }^{8}$, Heping Zheng ${ }^{7,9^{*}}$ and Ligang Yang ${ }^{1,2,9^{*}}$ (D)

\begin{abstract}
Background: Antimicrobial resistance in M. genitalium is a growing clinical problem. We investigated the mutations associated with macrolide and fluoroquinolone resistance, two commonly used medical regimens for treatment in China. Our aim is to analyze the prevalence and diversity of mutations among M. genitalium-positive clinical specimens in Guangzhou, south China.

Methods: A total of 154 stored M. genitalium positive specimens from men and women attending a STI clinic were tested for macrolide and fluoroquinolone mutations. M. genitalium was detected via TaqMan MGB real-time PCR. Mutations associated with macrolide resistance were detected using primers targeting region $V$ of the $23 S$ rRNA gene.

Fluoroquinolone resistant mutations were screened via primers targeting topoisomerase IV (parC) and DNA gyrase (gyrA).

Results: 98.7\% (152/154), 95.5\% (147/154) and 90.3\% (139/154) of M. genitalium positive samples produced sufficient amplicon for detecting resistance mutations in $23 \mathrm{~S}$ rRNA, gyrA and parC genes, respectively. 66.4\% (101/152), 0.7\% (1/147) and $77.7 \%$ (108/139) samples manifested mutations in 235 rRNA, gyrA and parC genes, respectively. A2072G (59/101, 58.4\%) and S83I (79/108, 73.1\%) were highly predominating in 23S rRNA and parC genes, respectively. Two samples had amino acid substitutions in gyrA (M95I and A96T, respectively). Two samples had two amino acid substitutions in parC (S83I + D87Y). 48.6\% (67/138) of samples harbored both macrolide and fluoroquinolone resistance-associated mutations. The most common combination of mutations was A2072G (23S rRNA) and S83I (parC) (40/67, 59.7\%). One sample had three amino acid changes in $23 \mathrm{~S} r \mathrm{RNA}$, gyrA and parC genes (A2072G + A96T + S831).

(Continued on next page)
\end{abstract}

\footnotetext{
*Correspondence: zhhpf@hotmail.com; yanglg3@hotmail.com

+Wujian Ke, Dongling Li, Lai Sze Tso and Ran Wei contributed equally to this

work.

${ }^{7}$ Clinical Laboratory, Dermatology Hospital, Southern Medical University,

Guangzhou 510095, China

'Department of Sexually Transmitted Diseases, Dermatology Hospital,

Southern Medical University, Guangzhou 510095, China

Full list of author information is available at the end of the article
} 
(Continued from previous page)

Conclusions: The high antimicrobial resistance rate of $M$. genitalium in Guangzhou is a very worrying problem and suggests that antimicrobial resistance testing and the development of new antibiotic regimens are crucially needed.

Keywords: Antimicrobial resistance, Macrolide, Fluoroquinolone, Mutations, Sexually transmitted infection, Mycoplasma genitalium, 23S rRNA, gyrA, parC, Guangzhou, China

\section{Background}

Antimicrobial resistance (AMR) of Mycoplasma genitalium (M. genitalium) is a growing problem with global implications for clinical guidelines and treatment [1-6]. As Jensen and Bradshaw (2015) argue, clinical monitoring and effective reporting on antimicrobial resistancemediating mutations in $M$. genitalium across geographic regions and populations are crucial for developing effective treatments in managing $M$. genitalium infections and AMR-mediation across global settings [7]. Yet, despite being one of the most populous countries in the world, there is sparse data on the prevalence of AMR-related mutations in China. Here, we contribute to global efforts to address this gap in AMR surveillance. We investigate the rates of AMR mutations associated with macrolide and fluoroquinolone treatment failure in M. genitalium, expanding the discussion on the use of these antibiotics in Guangzhou, China. Given these alarmingly high rates, it is very important to understand the background of antibiotic use in this region.

M. genitalium can result in urethritis [8], Mucopurulent cervicitis (MPC) [9], endometritis [10], and pelvic inflammatory disease (PID) [11-13]. M. genitalium is also a suspected cause of reactive arthritis and proctitis [14]. Characteristics contributing to increased risk of $M$. genitalium infections include living in low-and-middleincome localities [15-18], experiencing fertility problems for both men [19, 20] and women [21], abnormal pregnancy status [22], and being members of vulnerable populations, including men-who-have-sex-with men (MSM) [23, 24], female sex workers (FSW) [25], and people living with HIV [26]. These considerations have spurred clinicians and public health agencies to call for global coordination of $M$. genitalium guidelines and treatment to help mitigate AMR-related problems [1-6].

Due to the lack of a cell wall, the treatment choice of $M$. genitalium was limited to tetracyclines, macrolides, or later-generation fluoroquinolones [7, 27]. According to the 2016 European NGU guidelines, patients with urethritis should be tested for C. trachomatis and M. genitalium via nucleic acid amplification testing [28]. Since a single-dose treatment of azithromycin may result in the development of antimicrobial resistance in $M$. genitalium [29], the 2015 UK NGU guidelines, the 2016 European M. genitalium guidelines and the Australian STI management guidelines (2018) no longer recommend azithromycin $1 \mathrm{~g}$ as first line therapy [30-32]. Hence, it is troubling that mounting evidence indicates $M$. genitalium drug-resistance increases with even just a singledose treatment of azithromycin [2, 33-35]. Although a single dose of AZM can result in the development of resistance, AZM can be used in conjunction with doxycycline for susceptible infections (no 23S mutation, where screening is available). The fluoroquinolone moxifloxacin, another medication extensively used as a secondline bactericidal, has a cure rate approaching $100 \%$ in infections with susceptible strains [36]. In recent years, a decline in the efficacy of moxifloxacin has also been noted, first in Japan [7] then in Australia [37-39]. The elimination rate of moxifloxacin for M. genitalium infection has decreased from 100 to $89 \%$ since 2010 [37].

Genetically, mutations resulting in macrolide resistance are primarily attributed to single-nucleotide polymorphism (SNP) at positions A2071 or A2072 in region $\mathrm{V}$ of the $23 \mathrm{~S}$ rRNA gene $[2,40]$. Fluoroquinolone resistance is attributed to alternations of the gyrA subunit in DNA gyrase (which is composed of two gyrA and two gyrB subunits), or the parC subunit of topoisomerase IV (which is composed of two parC and two parE subunits) [41]. Compared with parC mutations, gyrA mutations likely have a less-severe effect on reducing the susceptibility of the bacterium for fluoroquinolone [42, 43]. Moxifloxacin resistant $M$. genitalium isolates, primarily causing amino acid changes at positions S83 and D87 (M. genitalium numbering) of parC, are similar to those found in other fluoroquinolone resistant bacteria [33, 44-46]. AMR studies of fluoroquinolone resistance in M. genitalium DNA tend to amplify the quinolone-resistance determining region (QRDR) of the gyrA gene and the corresponding region of the parC gene from M. genitalium DNA [47]. Antibiotic resistance of $M$. genitalium to both macrolides and quinolones have been found in Japan, Australia, and New Zealand since 2008 [33, 38, 44, 48, 49]. This disturbing trend suggests that the AMR dilemma attributable to $M$. genitalium is spreading and becoming even more virulent $[33,44,48,49]$.

Clinical monitoring and effective reporting of findings and research of antimicrobial resistance-mediating mutations in M. genitalium across geographic regions and populations are crucial for the development of efficacious treatment for combating M. genitalium infections and managing AMR across global settings [7]. Unfortunately, 
there is sparse data and low awareness of the patterns of antimicrobial resistance of $M$. genitalium in China. The aim of this study is to support and contribute to AMR research by analyzing the prevalence and diversity of mutations associated with macrolide and fluoroquinolone resistance among M. genitalium in positive clinical specimens in Guangzhou, China.

\section{Methods}

\section{Study population and specimens}

A total of $154 M$. genitalium positive clinical specimens were collected from patients attending a STI clinic at Dermatology Hospital, Southern Medical University, Guangzhou, China. The collecting period was from December 2016 to December 2018. The samples included urethral swabs and/or rectal swabs from male patients and cervical swabs from female patients.

M. genitalium was detected via TaqMan MGB realtime polymerase chain reaction (PCR) as described by Jensen et al. [50]. DNA extracted by using DNA extraction kit (Suzhou Bacme Biotech Co.) from M. genitalium positive samples were tested for the mutations associated with macrolide and quinolone resistance in the same day or stored at $-20^{\circ} \mathrm{C}$ prior to testing. Samples in our study were collected with the permission of STI patients as part of standard protocol for diagnostics and treatment. Specimens were then processed and stored with no identifiable patient data. As part of hospital protocol, de-identified patient samples are stored in the STI clinic biobank for surveillance, diagnosis, and research purposes. This study utilizes specimens from this biobank.

\section{Detection of macrolide and fluoroquinolone resistance- associated mutations in 235 rRNA, gyrA, and parC} From extracted DNA, mutations associated with macrolide resistance were detected using primers targeting region $\mathrm{V}$ of the $23 \mathrm{~S}$ rRNA gene (nucleotides 1992-2138) [40]. Fluoroquinolone resistance mutations in the gyrA (nucleotides 172-402) and parC (nucleotides 164-483) genes were screened using primers as reported previously [51, 52]. Details of the primer sequencing and thermo-cycling parameters for amplification are provided in Table 1.

Each reaction volume of $25 \mu \mathrm{l}$ contained $10 \times$ PCR buffer (without $\mathrm{Mg} 2+$ : $100 \mathrm{mM}$ Tris- $\mathrm{HCl} \mathrm{pH} 8.8$ at $25^{\circ} \mathrm{C}$; $500 \mathrm{mM} \mathrm{KCl}, 0.8 \%(\mathrm{v} / \mathrm{v})$ Nonidet), $0.6 \mu \mathrm{M}$ each forward and reverse primer, $0.5 \mu \mathrm{l} \mathrm{dNTP} 10 \mathrm{mM}, 1 \mathrm{U}$ of $\mathrm{P} f u$ DNA polymerase (Invitrogen) and sterile water. Confirmation of PCR product was achieved by using an agarose gel (1.5\%) electrophoresis. Amplified fragments were purified by QIAquick PCR Purification Kit (QIAG EN). Sequencing services were purchased and outsourced to Sangon Biotech, China. Samples were sequenced in both directions.

\section{Data analysis}

The mutation sequencing data in $23 \mathrm{~S}$ rRNA, gyrA and parC genes from M. genitalium positive DNA specimens were analyzed with the software program BioEdit (http://www.mbio.ncsu.edu/bioedit/bioedit.html). The genome sequence of $M$. genitalium strain G37 (GenBank accession no. NC_000908.2) was used as a reference strain. Amino acid changes in the QRDRs of the gyrA and $\operatorname{par} C$ genes in this study were compared with previous studies [6, 24, 26, 33, 38, 41].

\section{Ethics approval}

The study was approved by the Ethics Committee of Dermatology Hospital of Southern Medical University (approval no. GDDHLS - 20,171,203, 13/12/2017). Informed consent was waived as the committee believes that this research presents no potential risk because the study does not contain identifiable data that would cause harm or result in a breach of confidentiality.

\section{Results}

Laboratory results of AMR mutations in M. genitalium

A total of 154 M. genitalium DNA-positive samples were stored during the collection period (December 2016-December 2018). Of these, 98.7\% (152/154), 95.5\% (147/ $154)$ and $90.3 \%$ (139/154) produced sufficient amplicon for detecting resistance mutations in $23 \mathrm{~S}$ rRNA, gyrA and $\operatorname{parC}$ genes, respectively.

Results are summarized in Table 2.

Among 152 samples, 66.4\% (101/152) harbored mutations in the $23 \mathrm{~S}$ rRNA gene, and $33.6 \%$ were wild type. The mutation A2072G $(n=59)$ was highly predominating in Guangzhou, accounting for 58.4\% (59/101) of the cases found positive for nucleotide substitutions in the 23S rRNA gene. Other detectable mutations included A2071G $(n=21)$, A2071T $(n=20)$, and A2072C $(n=1)$.

Although, none of the gyrA mutations have been associated with increased fluoroquinolone MICs, amino acid alterations in gyrA (M95I, A96T) were only detected in two samples. To our knowledge, this specific amino acid change (A96T) has not been reported elsewhere in the AMR literature. However, mutation at the next position (99 in $g y r A$ ) have been described in previous reports, and the positions are within the QRDRs, indicating its association with fluoroquinolone resistance [45]. Mutations of parC at positions S83 (except S83N) and D87 have been associated with increased MICs of moxifloxacin and parC mutations typically associated with fluoroquinolone resistance were detected in $77.7 \%$ (108/139) of samples. Of these, the most frequent mutation was S83I $(n=79)$, accounting for $73.1 \%$ of 108 samples. In two samples, two amino acid substitutions in parC $(\mathrm{S} 83 \mathrm{I}+\mathrm{D} 87 \mathrm{Y})$ were present. As shown in Table 2, substitutions in $\operatorname{parC}$ are more common than in $g y r A$. 
Table 1 Primer sequences and thermo-cycling parameters for amplification of resistance-determining regions.

\begin{tabular}{|c|c|c|c|}
\hline Forward primer (5'-3') & Reverse primer (5'-3') & $\begin{array}{c}\text { Fragment } \\
\text { Length }\end{array}$ & $\begin{array}{c}\text { Thermo-cycling } \\
\text { parameters }\end{array}$ \\
\hline $23 s-1992 F$ & 23S-2138R & \multirow[b]{2}{*}{$147 \mathrm{bp}$} & \\
\hline CCATCTCTTGACTGTCTCGGCTAT & CCTACCTATTCTCTACATGGTGGTGTT & & $95^{\circ} \mathrm{C}-3$ min-denaturing \\
\hline gyrA-F & $\operatorname{gyr} A-\mathrm{R}$ & \multirow{3}{*}{$300 \mathrm{bp}$} & $94^{\circ} \mathrm{C}-30 \mathrm{sec}$ \\
\hline CCTGATGCTAGAGATGGACTTAAA & AAGTTCTGCTGCAAGTTTAGATAAT & & $58^{\circ} \mathrm{C}-30 \mathrm{sec}$ \\
\hline $\operatorname{par} C-\mathrm{F}$ & $\operatorname{parC}-\mathbf{R}$ & & $72^{\circ} \mathrm{C}-30 \mathrm{sec}$ \\
\hline TGGGCTTAAAACCCACCACT & CGGGTTTCTGTGTAACGCAT & $214 \mathrm{bp}$ & $72^{\circ} \mathrm{C}-10$ min-extension \\
\hline
\end{tabular}

bp base pair

Table 2 Prevalence of mutations associated to macrolide and fluoroquinolone resistance from $154 \mathrm{M}$. genitalium positive samples in Guangzhou, China, 2016-2018

\begin{tabular}{|c|c|c|c|}
\hline Gene & $S N P^{a}$ & $\begin{array}{l}\text { Amino acid } \\
\text { change }\end{array}$ & $\begin{array}{l}\text { Frequency, \% (No. of samples containing mutation(s) or wild type / No. of successfully } \\
\text { sequenced samples) }\end{array}$ \\
\hline \multirow[t]{5}{*}{$\begin{array}{l}23 S \\
\text { rRNA }\end{array}$} & $\begin{array}{l}\mathrm{A}-2071 \rightarrow \\
\mathrm{G}\end{array}$ & $-b$ & $13.8(21 / 152)$ \\
\hline & $\begin{array}{l}\text { A-2071 } \rightarrow \\
T\end{array}$ & - & $13.2(20 / 152)$ \\
\hline & $\begin{array}{l}\mathrm{A}-2072 \rightarrow \\
\mathrm{G}\end{array}$ & - & $38.8(59 / 152)$ \\
\hline & $\begin{array}{l}\text { A-2072 } \rightarrow \\
\text { C }\end{array}$ & - & $0.7(1 / 152)$ \\
\hline & Wild type & - & $33.6(51 / 152)$ \\
\hline \multirow[t]{3}{*}{ gyrA } & $\mathrm{G}-285 \rightarrow \mathrm{C}$ & $M-95 \rightarrow I$ & $0.7(1 / 147)$ \\
\hline & $\mathrm{G}-286 \rightarrow \mathrm{A}$ & $A-96 \rightarrow T$ & $0.7(1 / 147)$ \\
\hline & Wild type & - & $98.6(145 / 147)$ \\
\hline \multirow[t]{12}{*}{ parc } & $C-234 \rightarrow T$ & No change & $0.7(1 / 139)$ \\
\hline & $\mathrm{G}-241 \rightarrow \mathrm{T}$ & $\mathrm{G}-81 \rightarrow \mathrm{T}$ & $0.7(1 / 139)$ \\
\hline & $\mathrm{A}-247 \rightarrow \mathrm{C}$ & $\mathrm{S}-83 \rightarrow \mathrm{R}$ & $2.2(3 / 139)$ \\
\hline & $\mathrm{G}-248 \rightarrow \mathrm{A}$ & $\mathrm{S}-83 \rightarrow \mathrm{N}$ & $5.8(8 / 139)$ \\
\hline & $\mathrm{G}-248 \rightarrow \mathrm{T}$ & $\mathrm{S}-83 \rightarrow \mathrm{I}$ & $56.8(79 / 139)$ \\
\hline & $\mathrm{T}-249 \rightarrow \mathrm{A}$ & $\mathrm{S}-83 \rightarrow \mathrm{R}$ & $1.4(2 / 139)$ \\
\hline & $\mathrm{G}-259 \rightarrow \mathrm{T}$ & $\mathrm{D}-87 \rightarrow \mathrm{Y}$ & $2.9(4 / 139)$ \\
\hline & $G-259 \rightarrow A$ & $\mathrm{D}-87 \rightarrow \mathrm{N}$ & $2.2(3 / 139)$ \\
\hline & $A-260 \rightarrow G$ & $\mathrm{D}-87 \rightarrow \mathrm{G}$ & $2.9(4 / 139)$ \\
\hline & $\mathrm{T}-267 \rightarrow \mathrm{C}$ & No change & $0.7(1 / 139)$ \\
\hline & $\begin{array}{l}\mathrm{G}-248 \rightarrow \mathrm{T} \\
+ \\
\mathrm{G}-259 \rightarrow \mathrm{T}\end{array}$ & $\begin{array}{l}S-83 \rightarrow \mid+D- \\
87 \rightarrow Y\end{array}$ & $1.4(2 / 139)$ \\
\hline & Wild type & - & $22.3(31 / 139)$ \\
\hline
\end{tabular}

a Nucleotide positions in 23S rRNA and in gyrA and parC genes are given according to the M. genitalium G37 genome (GenBank accession no. NC_000908.2). SNP single-nucleotide polymorphism, $r R N A$ ribosomal ribonucleic acid, $b$, no amino acid change 
Of the 138 samples undergoing complete analysis for both the $23 \mathrm{~s}$ RNA and $\operatorname{parC}$ genes, $48.6 \%$ (67/138) harbored both macrolide and fluoroquinolone resistanceassociated mutations. Combining the 23S rRNA and $\operatorname{parC}$ mutations, 15 genotypes were identified (Table 3 ).

\section{Discussion}

The mutations in $23 \mathrm{~S}$ rRNA and parC have been identified as the cause of failure of macrolide and quinolone in the treatment of $M$. genitalium [53, 54]. In our study, $66.4 \%(101 / 152)$ and $77.7 \%(108 / 139)$ of samples manifested mutations in $23 \mathrm{~S}$ rRNA and parC genes, and A2072G (59/101, 58.4\%) and S83I (79/108, 73.1\%) were highly predominating in $23 \mathrm{~S}$ rRNA and parC genes, respectively. More worryingly, the proportion of mutations in both $23 \mathrm{~S}$ rRNA and parC genes was as high as $48.6 \%$. This suggests that nearly half of these samples are resistant to both macrolide and quinolones. We also reported other mutations in parC and gyrA genes. However, the significance of these mutations requires further study.

Within the last 10 years, $M$. genitalium eradication rate has declined gradually $[55,56]$. The resistance rate of $M$. genitalium has been described as a rising phenomenon in many countries $[42,57]$. At the time of this study, there are only three locations actively conducting AMRrelated research in clinical settings in China. The earliest published macrolide-associated mutations in M.genitalium in China collected samples from 18 symptomatic NGU patients [58]. In this research, the 23S rRNA

Table 3 Prevalence of 235 rRNA gene and parC mutations among $M$. genitalium positive samples with possible multidrug resistance in Guangzhou, China, 2016-2018

\begin{tabular}{ll}
\hline Mutations $^{\mathbf{a}}$ & Count (\%) $^{\mathbf{b}}$ \\
\hline A2071G + S83I & $8(5.8)$ \\
A2071G + S83R & $2(1.4)$ \\
A2071G + S83N & $1(0.7)$ \\
A2071G + D87G & $1(0.7)$ \\
A2071G + D87N & $1(0.7)$ \\
A2071T + S83I & $1(0.7)$ \\
A2071T + S83R & $2(1.4)$ \\
A2071T + D87N & $1(0.7)$ \\
A2071T + D87Y & $1(0.7)$ \\
A2072G + G81C & $1(0.7)$ \\
A2072G + S831 & $40(29.0)$ \\
A2072G + S83R & $3(2.2)$ \\
A2072G + S83N & $1(0.7)$ \\
A2072G + D87Y & $3(2.2)$ \\
A2072G + S83I + D87Y & $1(0.7)$ \\
\hline
\end{tabular}

${ }^{a}$ Nucleotide positions in 23S rRNA and in parC gene are listed in accordance to the $M$. genitalium G37 genome (GenBank accession no. NC_000908.2). ${ }^{b}$ Only 138 successfully sequenced samples included mutation rate was $94.4 \%$, with A2072G being the most common (55.6\%), A2071G the second most (27.8\%), and A2071T as the third most common mutation (11.1\%), with no double-mutations detectable [58]. Later, in the same hospital, $358 \mathrm{M}$. genitalium positive samples were collected. The $23 \mathrm{~S}$ rRNA mutation rate was $88.9 \%$, with A2072G being the most common (61.9\%), A2071G the second most (17.6\%), and no double-mutations were detected [59]. The parC mutation rate was $90.4 \%$, S83 $\rightarrow \mathrm{I}$ was the most common mutation (83.7\%) [59]. The double mutation in $\operatorname{parC}(\mathrm{G} 248 \mathrm{~A}+\mathrm{G} 259 \mathrm{~T})$ was detected [59]. The gyrA mutation rate was $13.0 \%$, with M95 $\rightarrow$ I being the most common (5.3\%), three double-mutations in G244A + G285A, G285A + A309G, and G285A + A317G were detectable [59]. Another earlier study collected samples among men seeking care at an infertility clinic in Changsha, a city in the interior of China [60]. The macrolide mutations rate was similarly extremely high at $96.7 \%$ [60]. The two most common mutations in the Nanjing study are also the most frequent mutations in Changsha, that is, A2072G (60.0\%) and A2071G (20.0\%) [60]. Unlike in Nanjing, the analysis conducted on specimens from Changsha detected double-mutations, and these mutations are frequent enough to be the third most common set of mutations (A2071T + A2072G at 11.7\%). Our location, a STI center based in a hospital in Guangzhou, constitutes the third AMR site. Our facility is a provincial STI center situated in Guangzhou, the capital city of Guangdong Province. Guangzhou is an international hub for travel, trade, and commerce and a major destination for migrants and their concomitant illnesses. Servicing the medical needs of such a diverse population, we focus on macrolide and fluoroquinolone resistance-associated mutations in M. genitalium. We extend current knowledge in two key ways. First, we continue monitoring and reporting efforts on macrolide and fluoroquinolone resistance, expanding on reports from the two prior studies based in central and interior China, by adding a major urban migration destination in south China. Second, we expand on AMR surveillance by being the first to report on macrolide and fluoroquinolone-associated mutations in men and women in China.

The 23S rRNA mutation is associated with macrolide resistance [61]. We found that SNPs in region V of the $23 \mathrm{~S}$ rRNA gene were observed in 101 (66.4\%) samples from male and female patients with $M$. genitalium-positive infection in 2016-2018. Mutations mainly occurred at positions A2071 and A2072 mainly to G (C or T is relatively less). With the exception of a study from Greenland, the mutation frequency (66.4\%) [62] observed was higher than frequencies reported by Russia and Estonia $(0.7 \sim 10 \%)$ [63], South Africa (10\%) [64], southern Sweden (13\%) [65], France (17\%) [66], Japan (42.2\%) [42], southern USA (48\%) [67], Norway (56\%) [68], and Denmark (57\%) [68]. 
However, our rate of $66.4 \%$ is lower than rates reported from England (82.4\%) [69], the US (Alabama: 74.1\% HIV positive MSM) [26], and Australia (79.4\%) [70].

It is widely reported that $M$. genitalium expressed a diversity of mutations linked to fluoroquinolone resistance-associated in $\operatorname{gyr}$ and parC gene $[49,53,68]$. Similar to extant studies, mutations in the QRDR of the gyrA gene of our samples were rarely detected [53, 71]. The amino acid changes $(\mathrm{M} 95 \rightarrow \mathrm{I}$ and $\mathrm{A} 96 \rightarrow \mathrm{T})$ in gyrA were found in our specimens. The $\mathrm{M}$ to I transition at position 95 of $\operatorname{gyrA}$ ( $\mathrm{G}$ to $\mathrm{C}$ at nucleotide position 285) was first reported in 2013 by Tagg et al. [49], most commonly observed from 2013 to 2017 in Japan, and have been reported in moxifloxacin-resistant strains of M. pneumoniae, M. hominis, and Ureaplasma spp [49, 57, 72, 73]. To our knowledge, a gyrA A96 $\rightarrow$ T mutation in the core of the QRDR has not previously been described in M. genitalium and its association with resistance to fluoroquinolone remains unknown. The amino acid changes at G81, S83 and D87, have been previously reported as being associated with fluoroquinolone resistance in $M$. genitalium and other closely related organisms [44, 46, 49]. Although the majority of published reports have shown the parC S83N and S83I substitution as the two most prevalent base changes at position 248, we find that the S83I substitution accounted for $71.8 \%$ (79/110), significantly higher than reports from Japan (13.0-23.2\%) [42], New Zealand (16.7\%) [48], and southwestern France (9.1\%) [66]. Among the 139 samples successfully amplified DNA sequences of parC gene, we observed an exorbitantly high mutation rate of $77.7 \%$.

Additionally, $48.6 \%(67 / 138)$ of samples were multidrug resistant and contained both macrolide and fluoroquinolone resistance related SNPs. If SNP on parC is strictly limited to S83I, the multidrug resistance rate was $36.1 \%$ (50/138). In Japan, the prevalence of multidrug resistance with A2071G or A2072G in the 23S rRNA and amino-acid change in S83 or D87 of parC has been reported in up to $21.8 \%$ from 2010 to 2017 [42]. Our data showed very high prevalence $(47.8 \%)$ of the same mutation. This trend of multidrug resistance presents challenges for clinicians because of a lack of suitable alternative therapy after azithromycin and moxifloxacin failure. Pristinamycin as the only third-line treatment has been reported to be only about $75 \%$ effective and is not readily available in China [27].

The high prevalence of mutations in macrolide and quinolone resistance-associated genes observed in our study might be related to the study population and to antibiotic overuse in China. The clinical samples were collected from the STI clinic of Dermatology Hospital, Southern Medical University. As a provincial level STI center, our doctors are referred patients from all over the region when doctors from feeder hospitals are unable to resolve medical ailments locally. These patients likely experienced several prior courses of antibiotic treatment. In addition, in China, it is incredibly easy for the public to obtain antibiotic prescriptions and purchase antibiotics in pharmacies. Data show that antibiotic use in children and hospitalized patients in China is very high [74]. These factors further exacerbate the problems of antibiotics resistance confronting health facilities today [75].

\section{Limitations}

An important limitation of the study is the lack of epidemiological and clinical information, as well as information about treatment received and clinical evolution of the patients. The significance of several novel mutations in the parC and gyrA genes remains unknown. Nonetheless, the prevalence of mutations associated to macrolide and fluoroquinolone resistance in our study related to phenotypic testing has been previously reported in several studies. Our prevalence rate is a calculation based on a sample of patients seen by clinicians at our STI clinic. During patient intake and consultation, we did not collect patients' history of previous antibiotic use. We hypothesized that patients at our STI clinic were more likely to have previously used antibiotics than the general population, so there might be a possibility of overestimating the prevalence rate when extended to the general population. Secondarily, we lack data for a large sample epidemiological survey of $M$. genitalium, since samples studied were collected mainly from a single clinic. Hence, our findings might not be representative or readily generalizable to the larger population living in Guangzhou.

\section{Conclusions}

In conclusion, the high mutation rate of M. genitalium reported in this study is a very worrying problem. For patients with $M$. genitalium infection, antimicrobial resistance testing is crucial. The occurrence of drugresistant strains is of great public health concern. The development of new antibiotic regimens for M. genitalium infections are urgently needed.

\section{Abbreviations \\ AMR: antimicrobial resistance; DNA: Deoxyribonucleic acid; FSW: Female sex worker; HIV: Human immunodeficiency virus; MPC: Mucopurulent cervicitis; M. genitalium: Mycoplasma genitalium; M. hominis: Mycoplasma hominis; M. pneumonia: Mycoplasma pneumonia; MSM: Men who have sex with men; NAAT: Nucleic acid amplification testing; TaqMan MGB: TaqMan minor groove binder; PCR: Polymerase Chain Reaction; PID: Pelvic inflammatory disease; QRDRs: Quinolone resistance-determining regions; rRNA: Ribosomal ribonucleic acid; SNPs: Single nucleotide polymorphisms; STI: Sexually Transmitted Infection}

\section{Acknowledgements}

We extent our thanks to all of the healthcare and laboratory staff at all levels, who participated in diagnoses, and in data collection for this study at the Dermatology Hospital, Southern Medical University.

Authors' contributions

Authors are cited in the same order that they are cited in the title page. WJK, DLL, RW analyzed the data and drafted the manuscript. ZYC, XHZ, LYW 
curated the data reviewed and edited the manuscript. YYL1, HRC, YHL performed the laboratory testing, collected and validated the data. CML, YYL2 collected and curated the data, drafted the manuscript, and secured funding. LST, HPZ, LGY provided overall leadership to the study, participated in the analysis, and secured funding. YYL1 corresponding to Yinyuan Lan and YYL2 corresponding to Yuying Liao. All authors have read and approved the final manuscript.

\section{Authors' information}

Authors are cited in the same order that they are cited in the title page.

\section{Funding}

This work was supported by the Bureau of Science and Information Technology of Guangzhou Municipality [201704020219]; Medical Science and Technology Foundation of Guangdong Province (CN) [A2017224 and A2018248]; High Level Project of Medicine in Longhua, Shenzhen [HLPM201907020105]; Basic and Clinical Research Training Project of Dermatology Hospital, Southern Medical University [C2019001]; Research Council of Norway [275002]. The funders had no role in study design, data collection and analysis, decision to publish, or preparation of the manuscript.

\section{Availability of data and materials}

The datasets generated and/or analysed during the current study are available in the GenBank repository, accession number to datasets are Banklt2402413, Banklt2402439 and Banklt2402448.

\section{Ethics approval and consent to participate}

The study was approved by the Ethics Committee of Dermatology Hospital of Southern Medical University (approval no. GDDHLS - 20171203, 13/12/ 2017). Informed consent was waived, because the committee believes that the research presents no potential risk for harm resulting from a breach of confidentiality.

\section{Consent for publication}

Not applicable.

\section{Competing interests}

The authors declare that they have no competing interest.

\section{Author details}

'Department of Sexually Transmitted Diseases, Dermatology Hospital, Southern Medical University, Guangzhou 510095, China. ${ }^{2}$ Department of Sexually Transmitted Diseases, Guangdong Provincial Dermatology Hospital, Guangzhou 510095, China. ${ }^{3}$ Department of Culture Studies and Oriental Languages, University of Oslo, 0315 Oslo, Norway. ${ }^{4}$ Anthropology, Massachusetts Institute of Technology, Cambridge, MA 02142, USA. ${ }^{5}$ Center for Health and Human Development Studies, Sun Yat-Sen University, Guangzhou 510275, China. ${ }^{6}$ Department of Dermatovenerology, Tianjin Medical University General Hospital, Tianjin 300052, China. ${ }^{7}$ Clinical Laboratory, Dermatology Hospital, Southern Medical University, Guangzhou 510095, China. ${ }^{8}$ Department of Dermatology, Qingyuan Chronic Disease Prevention Hospital, Qingyuan 511500, China. ${ }^{9}$ Dermatology Hospital, Southern Medical University, Guangzhou 510091, Guangdong, China.

Received: 17 January 2020 Accepted: 24 November 2020 Published online: 11 December 2020

\section{References}

1. Golden MR, Workowski KA, Bolan G. Developing a Public Health Response to Mycoplasma genitalium. J Infect Dis. 2017;216(suppl 2):S420-6.

2. Unemo $M$, Jensen JS. Antimicrobial-resistant sexually transmitted infections: gonorrhoea and mycoplasma genitalium. Nat Rev Urol. 2017;14(3):139-52.

3. Guschin A, Ryzhikh P, Rumyantseva T, et al. Treatment efficacy, treatment failures and selection of macrolide resistance in patients with high load of mycoplasma genitalium during treatment of male urethritis with josamycin. BMC Infect Dis. 2015:15:40.

4. Mondeja BA, Couri J, Rodríguez NM, et al. Macrolide-resistant mycoplasma genitalium infections in Cuban patients: an underestimated health problem. BMC Infect Dis. 2018;18(1):601.
5. Campos GB, Lobão TN, Selis NN, et al. Prevalence of mycoplasma genitalium and mycoplasma hominis in urogenital tract of Brazilian women. BMC Infect Dis. 2015;15:60.

6. Muller EE, Mahlangu MP, Lewis DA, et al. Macrolide and fluoroquinolone resistance-associated mutations in mycoplasma genitalium in Johannesburg, South Africa, 2007-2014. BMC Infect Dis. 2019;19(1):148.

7. Jensen JS, Bradshaw C. Management of mycoplasma genitalium infections can we hit a moving target? BMC Infect Dis. 2015;15:343.

8. Jensen JS. Mycoplasma genitalium: the aetiological agent of urethritis and other sexually transmitted diseases. J Eur Acad Dermatol Venereol. 2004; 18(1):1-11.

9. Manhart LE, Critchlow CW, Holmes KK, et al. Mucopurulent cervicitis and mycoplasma genitalium. J Infect Dis. 2003;187(4):650-7.

10. Cohen CR, Manhart LE, Bukusi EA, et al. Association between mycoplasma genitalium and acute endometritis. Lancet. 2002;359(9308):765-6.

11. Daley GM, Russell DB, Tabrizi SN, et al. Mycoplasma genitalium: a review. Int J STD AIDS. 2014;25(7):475-87.

12. Lis R, Rowhani-Rahbar A, Manhart LE. Mycoplasma genitalium infection and female reproductive tract disease: a meta-analysis. Clin Infect Dis. 2015;61(3): $418-26$

13. Lewis J, Horner PJ, White PJ. Incidence of Pelvic Inflammatory Disease Associated With Mycoplasma genitalium Infection: Evidence Synthesis of Cohort Study Data. Clin Infect Dis. 2020:ciaa419.

14. Taylor-Robinson D, Jensen JS. Mycoplasma genitalium: from Chrysalis to multicolored butterfly. Clin Microbiol Rev. 2011;24(3):498-514.

15. Baumann L, Cina M, Egli-Gany D, et al. Prevalence of mycoplasma genitalium in different population groups: systematic review and metaanalysis. Sex Transm Infect. 2018;94(4):255-62.

16. Andersen B, Sokolowski I, Østergaard L, et al. Mycoplasma genitalium: prevalence and behavioural risk factors in the general population. Sex Transm Infect. 2007:83(3):237-41.

17. Oakeshott $P$, Aghaizu A, Hay P, et al. Is mycoplasma genitalium in women the "new chlamydia?" a community-based prospective cohort study. Clin Infect Dis. 2010;51(10):1160-6.

18. Manhart LE, Holmes KK, Hughes JP, et al. Mycoplasma genitalium among young adults in the United States: an emerging sexually transmitted infection. Am J Public Health. 2007;97(6):1118-25.

19. Gdoura R, Kchaou W, Chaari C, et al. Ureaplasma urealyticum, Ureaplasma parvum, Mycoplasma hominis and Mycoplasma genitalium infections and semen quality of infertile men. BMC Infect Dis. 2007;7:129.

20. Al-Sweih NA, Al-Fadli AH, Omu AE, et al. Prevalence of chlamydia trachomatis, mycoplasma hominis, mycoplasma genitalium, and Ureaplasma urealyticum infections and seminal quality in infertile and fertile men in Kuwait. J Androl. 2012;33(6):1323-9.

21. Clausen HF, Fedder J, Drasbek M, et al. Serological investigation of mycoplasma genitalium in infertile women. Hum Reprod. 2001;16(9):1866-74.

22. Esteghamati A, Badamchi A, Naghdalipoor M, et al. Prevalence of mycoplasma genitalium and Ureaplasma urealyticum in pregnant women. Tehran Univ Med J. 2018;76(8):568-74.

23. Zhao N, Li KT, Gao YY, et al. Mycoplasma Genitalium and mycoplasma Hominis are prevalent and correlated with HIV risk in MSM: a cross-sectional study in Shenyang, China. BMC Infect Dis. 2019;19(1):494.

24. Barberá MJ, Fernández-Huerta M, Jensen JS, et al. Mycoplasma genitalium macrolide and Fluoroquinolone resistance: prevalence and risk factors among a 2013-2014 cohort of patients in Barcelona, Spain. Sex Transm Dis. 2017;44(8):457-62

25. Coorevits $L$, Traen A, Bingé $L$, et al. Macrolide resistance in mycoplasma genitalium from female sex workers in Belgium. J Glob Antimicrob Resist. 2018;12:149-52

26. Dionne-Odom J, Geisler WM, Aaron KJ, et al. High prevalence of multidrugresistant mycoplasma genitalium in human immunodeficiency virus-infected men who have sex with men in Alabama. Clin Infect Dis. 2018;66(5):796-8.

27. Bradshaw CS, Jensen JS, Waites KB. New horizons in mycoplasma genitalium treatment. J Infect Dis. 2017;216(Suppl 2):S412-9.

28. Horner PJ, Blee K, Falk L, et al. 2016 European guideline on the management of non-gonococcal urethritis. Int J STD AIDS. 2016;27(11):928-37.

29. Horner P, Ingle SM, Garrett F, et al. Which azithromycin regimen should be used for treating mycoplasma genitalium? A meta-analysis Sex. Transm Infect. 2018;94:14-20.

30. Horner P, Blee K, O'Mahony C, et al. 2015 UK National Guideline on the management of non-gonococcal urethritis. Int J STD AIDS. 2016;27(2):85-96. 
31. Jensen JS, Cusini M, Gomberg M, et al. 2016 European guideline on mycoplasma genitalium infections. J Eur Acad Dermatol Venereol. 2016; 30(10):1650-6.

32. Australian STI management guidelines, online version, last updated on Wednesday, 11 July 2018. http://www.sti.guidelines.org.au/sexuallytransmissible-infections/mycoplasma-genitalium.

33. Murray GL, Bradshaw CS, Bissessor M, et al. Increasing macrolide and Fluoroquinolone resistance in mycoplasma genitalium. Emerg Infect Dis. 2017;23(5):809-12.

34. Wold C, Sorthe J, Hartgill U, et al. Identification of macrolide-resistant mycoplasma genitalium using real-time PCR. J Eur Acad Dermatol Venereol. 2015;29(8):1616-20.

35. Twin J, Jensen JS, Bradshaw CS, et al. Transmission and selection of macrolide resistant mycoplasma genitalium infections detected by rapid high resolution melt analysis. PLoS One. 2012;7(4):e35593.

36. Jernberg E, Moghaddam A, Moi H. Azithromycin and moxifloxacin for microbiological cure of mycoplasma genitalium infection: an open study. Int J STD AIDS. 2008;19(10):676-9.

37. Li Y, Le WJ, Li S, et al. Meta-analysis of the efficacy of moxifloxacin in treating mycoplasma genitalium infection. Int J STD AIDS. 2017;28(11):1106-14.

38. Sweeney EL, Trembizki $\mathrm{E}$, Bletchly $\mathrm{C}$, et al. Levels of mycoplasma genitalium antimicrobial resistance differ by both region and gender in the State of Queensland, Australia: implications for treatment guidelines. J Clin Microbiol. 2019;57(3):e01555-18.

39. Trembizki E, Buckley C, Bletchly C, et al. High levels of macrolide-resistant mycoplasma genitalium in Queensland, Australia. J Med Microbiol. 2017; 66(10):1451-3.

40. Jensen JS, Bradshaw CS, Tabrizi SN, et al. Azithromycin treatment failure in mycoplasma genitalium-positive patients with nongonococcal urethritis is associated with induced macrolide resistance. Clin Infect Dis. 2008;47(12):1546-53.

41. Bebear CM, Renaudin J, Charron A, et al. Mutations in the gyrA, parC, and parE genes associated with fluoroquinolone resistance in clinical isolates of mycoplasma hominis. Antimicrob Agents Chemother. 1999;43(4):954-6.

42. Hamasuna R, Le PT, Kutsuna S, et al. Mutations in ParC and GyrA of moxifloxacin-resistant and susceptible mycoplasma genitalium strains. PLoS One. 2018;13(6):e0198355.

43. Aldred KJ, Kerns RJ, Osheroff N. Mechanism of quinolone action and resistance. Biochemistry. 2014;53:1565-74.

44. Kikuchi M, Ito S, Yasuda M, et al. Remarkable increase in fluoroquinoloneresistant mycoplasma genitalium in Japan. J Antimicrob Chemother. 2014; 69(9):2376-82

45. Deguchi $\mathrm{T}$, Ito $\mathrm{S}$, Yasuda M, et al. Emergence of mycoplasma genitalium with clinically significant fluoroquinolone resistance conferred by amino acid changes both in GyrA and ParC in Japan. J Infect Chemother. 2017;23(9):648-50.

46. Shimada Y, Deguchi T, Nakane K, et al. Emergence of clinical strains of mycoplasma genitalium harbouring alterations in ParC associated with fluoroquinolone resistance. Int J Antimicrob Agents. 2010;36(3):255-8.

47. Yoshida H, Bogaki M, Nakamura M, et al. Quinolone resistance-determining region in the DNA gyrase gyrA gene of Escherichia coli. Antimicrob Agents Chemother. 1990;34(6):1271-2.

48. Anderson T, Coughlan E, Werno A. Mycoplasma genitalium macrolide and Fluoroquinolone resistance detection and clinical implications in a selected cohort in New Zealand. J Clin Microbiol. 2017;55(11):3242-8.

49. Tagg KA, Jeoffreys NJ, Couldwell DL, et al. Fluoroquinolone and macrolide resistance-associated mutations in mycoplasma genitalium. J Clin Microbiol. 2013;51(7):2245-9.

50. Jensen JS, Björnelius E, Dohn B, et al. Use of TaqMan 5' nuclease real-time PCR for quantitative detection of mycoplasma genitalium DNA in males with and without urethritis who were attendees at a sexually transmitted disease clinic. J Clin Microbiol. 2004;42(2):683-92.

51. Deguchi T, Maeda S, Tamaki M, et al. Analysis of the gyrA and parC genes of mycoplasma genitalium detected in first-pass urine of men with nongonococcal urethritis before and after fluoroquinolone treatment. J Antimicrob Chemother. 2001;48(5):742-4.

52. Pond MJ, Nori AV, Witney AA, et al. High prevalence of antibiotic-resistant mycoplasma genitalium in nongonococcal urethritis: the need for routine testing and the inadequacy of current treatment options. Clin Infect Dis. 2014;58(5):631-7.

53. Deguchi T, Yasuda M, Horie K, et al. Drug resistance-associated mutations in mycoplasma genitalium in female sex workers, Japan. Emerg Infect Dis. 2015; 21(6):1062-4.
54. Machalek DA, Tao $Y$, Shilling $H$, et al. Prevalence of mutations associated with resistance to macrolides and fluoroquinolones in mycoplasma genitalium: a systematic review and meta-analysis. Lancet Infect Dis. 2020; S1473-3099(20):30154-7.

55. Bissessor M, Tabrizi SN, Twin J, et al. Macrolide resistance and azithromycin failure in a mycoplasma genitalium-infected cohort and response of azithromycin failures to alternative antibiotic regimens. Clin Infect Dis. 2015;60(8):1228-36.

56. Tabrizi SN, Su J, Bradshaw CS, et al. Prospective evaluation of ResistancePlus MG, a new multiplex quantitative PCR assay for detection of mycoplasma genitalium and macrolide resistance. J Clin Microbiol. 2017;55(6):1915-9.

57. Deguchi T, Ito S, Yasuda M, et al. Surveillance of the prevalence of macrolide and/or fluoroquinolone resistance-associated mutations in mycoplasma genitalium in Japan. J Infect Chemother. 2018;24(11):861-7.

58. Liu P, Jiang J, Zhang JP, et al. Detection of point mutations associated with macrolide resistance in Mycoplasma genitalium. Chin J Dermatol. 2014, 47(8): 551-554. (Chinese).

59. Li Y, Su X, Le W, et al. Mycoplasma genitalium in symptomatic male urethritis: macrolide use is associated with increased resistance. Clin Infect Dis. 2020;70(5):805-10.

60. Li WN, Shi L, Long XY, Li Y, Zhu WB, Liu G. Mycoplasma genitalium incidence, treatment failure, and resistance: a retrospective survey of men of infertile couples from a hospital in China. Andrology. 2020;8(1):91-100. https://doi.org/10.1111/andr.12646.

61. de Salazar A, Barrientos-Durán A, Espadafor B, Fuentes-López A, Chueca N, Garcia F. Macrolide and fluoroquinolone resistance of Mycoplasma genitalium in southern Spain, 2018-2019. Sex Transm Infect. 2020:sextrans2019-054386. https://doi.org/10.1136/sextrans-2019-054386.

62. Gesink DC, Mulvad G, Montgomery-Andersen R, et al. Mycoplasma genitalium presence, resistance and epidemiology in Greenland. Int J Circumpolar Health. 2012;71:1-8.

63. Shipitsyna E, Rumyantseva T, Golparian D, et al. Prevalence of macrolide and fluoroquinolone resistance-mediating mutations in mycoplasma genitalium in five cities in Russia and Estonia. PLoS One. 2017;12(4):e0175763.

64. Hay B, Dubbink JH, Ouburg S, et al. Prevalence and macrolide resistance of mycoplasma genitalium in south African women. Sex Transm Dis. 2015;42(3):140-2.

65. Forslund $\mathrm{O}$, Hjelm M, El-Ali R, et al. Mycoplasma genitalium and macrolide resistance-associated mutations in the Skåne region of southern Sweden 2015. Acta Derm Venereol. 2017:97(10):1235-8.

66. Le Roy C, Hénin N, Pereyre S, et al. Fluoroquinolone-Resistant Mycoplasma genitalium. Southwestern France. Emerg Infect Dis. 2016;22(9):1677-9.

67. Getman D, Jiang A, O'Donnell M, et al. Mycoplasma genitalium prevalence, Coinfection, and macrolide antibiotic resistance frequency in a multicenter clinical study cohort in the United States. J Clin Microbiol. 2016;54(9):2278-83.

68. Unemo M, Salado-Rasmussen K, Hansen M, et al. Clinical and analytical evaluation of the new Aptima mycoplasma genitalium assay, with data on M. genitalium prevalence and antimicrobial resistance in M. genitalium in Denmark, Norway and Sweden in 2016. Clin Microbiol Infect. 2018;24:533-9.

69. Pitt R, Fifer $H$, Woodford $N$, et al. Detection of markers predictive of macrolide and fluoroquinolone resistance in mycoplasma genitalium from patients attending sexual health services in England. Sex Transm Infect. 2018;94(1):9-13.

70. Couldwell DL, Jalocon D, Power M, et al. Mycoplasma genitalium: high prevalence of resistance to macrolides and frequent anorectal infection in men who have sex with men in western Sydney. Sex Transm Infect. 2018;94(6):406-10.

71. Dumke R, Thürmer A, Jacobs E. Emergence of mycoplasma genitalium strains showing mutations associated with macrolide and fluoroquinolone resistance in the region Dresden, Germany. Diagn Microbiol Infect Dis. 2016;86(2):221-3.

72. Gruson D, Pereyre S, Renaudin $\mathrm{H}$, et al. In vitro development of resistance to six and four fluoroquinolones in mycoplasma pneumoniae and mycoplasma hominis, respectively. Antimicrob Agents Chemother. 2005;49(3):1190-3.

73. Bébéar $\mathrm{CM}$, Renaudin $\mathrm{H}$, Charron A, et al. DNA gyrase and topoisomerase IV mutations in clinical isolates of Ureaplasma spp. and mycoplasma hominis resistant to fluoroquinolones. Antimicrob Agents Chemother. 2003;47(10):3323-5.

74. Zhang JS, Liu G, Zhang WS, et al. Antibiotic usage in Chinese children: a point prevalence survey. World J Pediatr. 2018;14(4):335-43.

75. Wang $L$, Zhang $X$, Liang $X$, et al. Addressing antimicrobial resistance in China: policy implementation in a complex context. Glob Health. 2016;12(1):30.

\section{Publisher's Note}

Springer Nature remains neutral with regard to jurisdictional claims in published maps and institutional affiliations. 